'A Acikgoz, ${ }^{2} \mathrm{~S}$ Yildiz. ${ }^{1}$ Eskisehir Osmangazi University, Eskisehir; ${ }^{2}$ sstanbul University Nursing Faculty, Istanbul, Turkey

The present study was experimentally conducted to compare the effects of open and closed system of aspiration on pain in newborns given mechanical ventilation. Study population comprised the babies hospitalized in the Newborn Intense Care Unit at Eskisehir Osmangazi University Medicine Faculty Hospital and study sample comprised 42 eligible babies hospitalized in NICU from December 2010 to December 2011. With random sampling, 20 babies were included to the closed-aspiration-system group and 22 to the openaspiration-system group. Aspiration process was recorded with a camera system. Intervention monitoring form that include oxygen saturation and vital findings, Data collection Form that includes the personal characteristics of the babies, and Newborn Pain/Agitation and Sedation Scale (N-PASS) that evaluate the pain response of the babies were used for data collection. Personal characteristics of the babies were acquired by an investigator from their medical records. Camera records were evaluated by two independent persons, the investigator and a newborn nurse, by using for the NPASS scores. Computerized data were analyzed with using percentile, mean, Standard deviation, chi-square, Student's-t, matched-t, Wilcoxon-Z, Mann-Whitney-U and Kruskall-Wallis tests. Results of the present study show no statistically difference between the experimental and control groups $(\mathrm{p}=0.194)$. N-PASS pain scores were significantly different between pre-intervention period and during the intervention in both groups $(p<0.001)$. In conclusion, we suggest that babies experience pain during the aspiration and although statistically indifferent, an open system of aspiration produces a somewhat higher pain compared the closed system of aspiration.

\section{NATONAL CLINICAL GUIDELINE FOR ASSESMENT OF PAIN IN NEONATES IN DENMARK}

doi:10.1136/archdischild-2012-302724.1900

H Haslund, Special Interest Group in Neonatal Nursing. NICU, Aalborg Sygehus, Aarhus University Anthropology Department, Aalborg, Denmark

Background Specific demands regarding pain management in Denmark require that Pain assessment must be conducted using evidence based standards. Until spring 2012 we did not have this in Denmark. A National Special Interest Group in Neonatal Nursing thus has developed a national clinical guideline on pain assessment for neonatal infants.

Methods This work has been carried out in collaboration with the national Clearing House for clinical guidelines to ensure methodological quality, and that recommendations reflect best evidence. A literature review was carried out and the validation of six pain score instruments was assessed. Clinical utility was also considered, as many NICUs in Denmark are inexperienced in pain assessment using a specific tool.

Results A national guideline on pain assessment for neonates recommending the use of COMFORTneo or alternatively PIIP is now being approved for use in Denmark.

The pain assessment tool will be implemented in many NICUs during summer 2012 .

Conclusion The work with conducting a national guideline is very demanding and academic research skills are needed. Even though it is time-consuming it is essential to have evidence based standards in order to deliver nurse care of high standard. The National Special Interest Group in Neonatal Nursing has arranged a national conference for neonatal nurses about pain assessment, as well as training in and implementation of the pain assessment tool in daily clinical work.
${ }^{1} \mathrm{C}$ Bellieni, ${ }^{2} \mathrm{G}$ Buonocore. ${ }^{1}$ Pediatrics, University Hospital Siena; ${ }^{2}$ University of Siena, Siena, Italy

Aim To compare pain during intramuscular injections (IMI) of antibiotics, with different analgesic methods.

Material and Methods We have studied 30 term babies who had to receive several IMI of antibiotic in the first week of life. During the IMI, an analgesic treatment was performed using

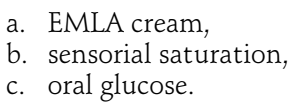

EMLA cream is an analgesic cream to be applied topically at least $30 \mathrm{~min}$ before the procedure. Sensorial saturation is a nonpharmacological procedure in which oral sugar, massage and voice are simultaneously used to antagonize pain. Oral glucose is a solution of $33 \%$ glucose in water, with well known analgesic activity. A pain score was giving to the reactions of each baby during the IMI, using a validated pain scale (DAN scale).

Results Mean pain scores were 6 (SD 2.1), 1.6 (SD 1.5) and 1 (SD 1.4) for EMLA, oral glucose and sensorial saturation respectively. EMLA score was significantly higher than the other types of analgesia.

Conclusion Nonpharmacologic procedures are effective in relieving IMI pain in newborns. EMLA cream is far less effective.

\section{NURSING CARE TO A CHILD WITH PHANTOM LIMB SYNDROME: A CASE REPORT}

doi:10.1136/archdischild-2012-302724.1902

II de Barbieri, ${ }^{2} \mathrm{E}$ Lofoco, ${ }^{2} \mathrm{~A}$ Zampieron. ${ }^{1}$ Terapia Intensiva Pediatrica, Azienda Ospedaliera di Padova; ${ }^{2}$ University of Padua, Padova, Italy

Background and Aims Analysis of a clinical case regarding an uncommon health problem in paediatric age, the amputation of a limb and the subsequent "phantom limb pain (PLP)". Aim of this work is to describe nursing care in a case of advanced nursing practice in PICU, with the need of multidisciplinary care and with multicultural implications.

Methods Case report.

Discussion The patient is a 9 years old child of Chinese nationality. She lives in Italy with her parents, has a hearing impaired brother and a disabled sister. The child had a road accident and suffered major injuries. Transferred to the PICU, the amputation of the lower right limb and a permanent tutor to the left limb were inevitable. After the surgery, the child suffered severe pain to the limbs and an onset of sepsis due to necrosis of the wounds. Treated with antibiotics, she recovered from the sepsis but the pain remained. The assessment data show nursing diagnosis related to the child and the family, from NANDA-I International taxonomy: Impaired physical mobility; Disturbed sensory perception; Disturbed body image; Acute pain, Post traumatic syndrome and Impaired parenting. For each of them the team identified related outcomes and nursing interventions (from NOC and NIC taxonomies)

Conclusions The analysis of the case and the literature review show a lack of literature about the care of PLP in paediatric care, especially in nursing field. Nurses should have a major role with this kind of patients, not limited to pain monitoring and drug therapy administration.

\section{EFFECT OF LULLABY MUSIC ON PAIN IN PRETEM INFANTS DURING VENIPUNCTURE}

doi:10.1136/archdischild-2012-302724.1903

'Z Amirkhanzadeh Barandouzi, 'M Keshavarz, ${ }^{2} \mathrm{H}$ Ashayeri, ${ }^{2} \mathrm{~A}$ Montazeri. ' $S$ Chool of Nursing and Midwifery; ${ }^{2}$ Tehran University of Medical Sciences, Tehran, Iran 
Background and Aims Preterm infants need effective pain management during and after the frequent painful procedures that guarantee their survival, whereas insufficient pain control may have negative impact on development of cognition, motor function and behaviour in preterm infants. The aim of this study was to assess the analgesic effect of lullaby music on pain score during venipuncture in preterm infants.

Methods 60 healthy preterm infants with a gestational age of 32-36 weeks randomly assigned to two groups in a double blind manner (30 in each group). For infants in experimental group lullaby music, with 40-50 db, was played 2 min before venipuncture. In control group, infants did not receive any intervention. For two groups, Two video systems were used to videotape the infant's face and monitor during study. pain scores were calculated by using Premature Infant Pain Profile (PIPP) before intervention, during the 30 sec after needle insertion, $30 \mathrm{sec}$ after removal needle and $10^{\text {th }} \mathrm{min}$ after the end of venipuncture.

Results During the $30 \mathrm{sec}$ after needle insertion, there was no significant decrease in pain score in experimental group to compare with control group ( $p=0.075)$ whereas $30 \mathrm{sec}$ after the end of venipuncture, reduction in pain score was observed in experimental group ( $\mathrm{p}=0.0001)$.

Conclusion In lullaby music group, reduction in pain score during venipuncure did not observe, but Immediately after the end of procedure, significantly pain score decreased. So duration of playing music can be affected on pain responses during venipuncture in preterm infants.

\section{THE EFFECTS OF CLOWN INTERVENTION ON FATIGUE IN CHILDREN WITH CANCER UNDERGOING CHEMOTHERAPY}

doi:10.1136/archdischild-2012-302724.1904

${ }^{1} \mathrm{~F}$ Petrangeli, ${ }^{1} \mathrm{~A}$ Sili, ${ }^{1} \mathrm{~F}$ D'Agostino, ${ }^{2} \mathrm{~T}$ Petrangeli, 'N Cittadini, 'E Antonacci, ${ }^{1} \mathrm{R}$ Alvaro. 'School of Nursing, University 'Tor Vergata' ${ }^{2}$ Department of Pediatric Hematology and Oncology, Bambino Gesù Children's Hospital, IRCCS, Rome, Italy

Background and Aims Many studies show that cancer-related fatigue is one of the most common symptoms experienced by children as a side effect of cancer therapy. This problem has recently grown considerably. Nurses envolve in assisting children and parents to face illness and treatment procedures. The aim of this study was to investigate whether clown intervention could reduce fatigue in children with cancer undergoing chemotherapy.

Methods Ninety-nine children (aged 7-18 years) with cancer and with at least one cycle of chemotherapy, and one of their parents, participated in the study:during their hospitalization 54 of them interacted with clowns in the ward, while 45 children did not get them. Fatigue as measured by PedsOL Multidimensional Fatigue Scale and structured cognitive interviews on clown therapy.

Results The results emphasized the relevance of clown intervention on the reduction of fatigue in children. The study shows that in the sample that received clown intervention, the fatigue score was better than appears in the sample without the support of this activity (77.4DS $\pm 13.9 v s 49.3 \mathrm{DS} \pm 9.9 \mathrm{p}=.000)$, and that cognitive fatigue domain had the least affected (90vs62), compared with general fatigue (73.4DS $\pm 16.9 \mathrm{vs} 49.2 \mathrm{DS} \pm 12.4$ ) and sleep fatigue (69DS $\pm 16.4 \mathrm{vs} 37.3 \mathrm{DS} \pm 11.5)$ domains. Age was a factor associated with a significant increase in the fatigue scores.

Conclusions Children that receive the clown's care has shown a lower fatigue. It is essential for healthcare professionals to consider the effect of chemotherapy on the children and to recognize the specific needs of this patient. Nurses should routinely screen pediatric patients for fatigue and intervene to minimize their impact using pharmacologic and nonpharmacologic strategies.
1905 “KEEPING THE FAMILY TOGETHER” VERSUS “THE WORST
JOURNEY OF OUR LIVES”: PARENTS TRAVELLING WITH
REGIONAL PAEDIATRIC INTENSIVE CARE TRANSPORT
TEAM

doi:10.1136/archdischild-2012-302724.1905

SL Barlow, K Claydon-Smith, S Santo, E Waltho, K Parkins. NWTS, Warrington, UK

Background From approximately 1.7 million children North West and North Wales (UK), 600-700 transferred annually from 31 hospitals into 2 regional PICs. PICS standards 2010 state "wherever possible and appropriate, parents should be given the option to accompany their child during transfer". Parental stress is increased by not being able to travel with their child (1). Pre-NWTS, unitbased PIC transport teams use of front-line ambulances precluded parents travelling with their child. North West and North Wales PIC Transport Service (NWTS) started November 2010, as single dedicated regional service. Our service level agreement with private ambulance provider states must have four seats to ensure minimum one parent can travel

Methods Prospective audit of NWTS database (first year). NWTS staff questionnaire.

Results 558 parents (100\%) offered opportunity to travel with their child, 328 accepted (58.8\%).

\section{Abstract 1905 Table 1}

\begin{tabular}{lllll}
\hline 1 Parent & 2 Parents & No Parents & Data missing & Team vetoed \\
\hline 287 & 41 & 123 & 56 & 4 \\
$51 \%$ & $7 \%$ & $22 \%$ & $10 \%$ & $1 \%$ \\
\hline
\end{tabular}

Pre-NWTS, staff voiced concerns particularly potential difficulties if child deteriorated during transfer with parents present. Post NWTS, majority of staff recognise positive benefits especially if child may not survive, and no adverse incidents reported relating to parents.

Conclusion Parental uptake of an opportunity to travel with their child is a ringing endorsement of our new policy. "NWTS not only kept our daughter alive, but kept our family together."

References 1 "The worst journey of our lives": parents' experiences of a specialised paediatric retrieval service. Intensive Crit Care Nurs. 2003 19(2):103-8 Colville G et al.

\section{ALL ABOARD: THE USE OF SIMULATION FOR EDUCATING THE MULTIDISCPLINARY RETRIEVAL TEAM WITHIN THE SOUTH THAMES RETRIEVAL SERVICE}

doi:10.1136/archdischild-2012-302724.1906

F Bickell, K McCulloch. PICU, Guy's \& St Thomas' NHS Foundation Trust, London, UK

Background This presentation will explore the evolution of retrieval team training from the inception of the service in 1998 to the present day.

Just as the service has expanded from its very early days when teams took plastic bags of potentially useful kit out in a taxi to the local hospitals so the training of teams has developed to ensure team members are as ready as possible for the varied experiences they may encounter when out on the road.

Method Recently we have introduced multidisciplinary simulation training where nurses, doctors and ambulance technicians are brought together and are exposed to realistic retrieval scenarios based upon real situations that teams have already encountered.

Although clinical issues are discussed during debriefing the team are also encouraged to explore the 'human factors' in each scenario and examine how they have influenced, both the outcome and dynamics of a situation, (Sherwood et al 2002). 